\title{
TEMPAT BERTELUR PENYU DI PULAU SALIBABU KABUPATEN TALAUD
}

\author{
(Turtle’s Nesting Sites on Salibabu Island Talaud Regency)
}

\author{
Enos M. Balaira ${ }^{1^{\star}}$, Farnis B. Boneka ${ }^{1}$, Billy T. Wagey ${ }^{1}$. \\ 1. Program Studi IImu Kelautan, Fakultas Perikanan dan IImu Kelautan, Universitas Sam \\ Ratulangi,Manado. \\ *e-mail : balairakenan@yahoo.co.id
}

Turtle declared a protected animal, however the nesting turtles is being neglected in the management of coastal areas; impact, nesting turtles impaired even shrinkage due to land conversion. Turtle laying eggs on the beach zone above the highest tide line, in the area where they hatched. Nesting turtles in general has not been documented. This study aims to document and general description state of nesting turtles on the island Salibabu, Talaud. Data was obtained through interviews with local residents who generally live in coastal areas. Local residents recognize three species of sea turtles or the green turtle Chelonia mydas, Eretmochelys imbricate or hawksbill and leatherback turtles or Dermochelys coriacea. Island Salibabu recorded ten nesting namely Kalongan Beach, Long sand beach, Rammenna Beach, Matandikka Beach, Apai Beach, Tarawatta Beach, Dingkaren Beach, White Sand Beachl Lairre Beach, Batupengan Beach. The layout of the nesting site in general outside the locality. The geographical position of each turtle nesting recorded and mapped. Vegetation growing around the nest site is dominated by coconut tree (Cocos nucifera), Pandan Beach (Pandanus tectorius). White sand and sediment grain size by category sand being. Nesting turtles should be used as a conservation area.

Keywords: Nesting Site, turtle, Salibabu Island.

Penyu telah dinyatakan sebagai zatwa lindung, namun tempat bertelur penyu terabaikan dalam pengelolaan wilayah pantai dan pesisir; dampaknya, tempat bertelur penyu mengalami gangguan bahkan penyusutan akibat konversi lahan wilayah pantai untuk berbagai peruntukkan. Penyu meletakkan telur di mintakat pantai di atas garis pasang tertinggi di wilayah di mana mereka ditetaskan. Tempat bertelur penyu pada umumnya belum terdokumentasi. Studi ini bertujuan untuk mendokumentasikan dan mendiskripsi keadaan umum lokasi bertelur penyu di Pulau Salibabu, Talaud. Data diperoleh melalui wawancara dengan warga lokal yang pada umumnya bermukim di wilayah pesisir. Warga lokal mengenal tiga jenis penyu yakni penyu hijau atau $C$. mydas, penyu sisik atau $E$. imbricate dan penyu belimbing atau $D$. coriacea. Di Pulau Salibabu tercatat sepuluh tempat bertelur yakni Pantai Kalongan, Pantai Pasir Panjang, Pantai Rammenna, Pantai Matandikka, Pantai Apai, Pantai Tarawatta, Patai Dingkaren, Pantai Pasir Putih, Pantai Lairre, Pantai Batupengan. Letak tempat bertelur tersebut pada umumnya di luar wilayah pemukiman. Posisi geografis setiap lokasi bertelur penyu dicatat dan telah dipetahkan. Vegetasi yang tumbuh di sekitar lokasi sarang didominasi oleh pohon Kelapa (C. nucifera), Pandan Pantai ( $P$. tectorius). Sedimen pasir berwarna putih dan berdasarkan ukuran butir termasuk kategori pasir sedang. Lokasi bertelur penyu patut dijadikan kawasan konservasi.

Kata Kunci : Tempat bertelur, Penyu, Pulau Salibabu 


\section{PENDAHULUAN}

Dari tuju jenis penyu yang masih eksis di dunia, enam terdapat di perairan Indonesia yakni penyu Hijau atau $C$ mydas Linnaeus 1758, penyu Sisik atau $E$ imbricate (Linnaeus, 1766), penyu Lekang atau Lepidochelys olivacea (Eschscholtz, 1829), penyu pipih atau Natator depressa (Garman, 1880), penyu Tempayan atau Caretta caretta (Linnaeus, 1758) dan penyu Belimbing atau $D$ coriacea (Vandelli, 1761) (DKP, 2009). Semua penyu ini telah dinyatakan sebagai zatwa yang dilindungi melalui konvensi Internasional dan sejumlah peraturan Nasional Indonesia. Namun penyu masih terus diburu oleh warga lokal sehingga populasi cenderung menurun. Penangkapan umumnya pada saat penyu beruaya ke lokasi bertelur. Warga talaud pada umunya belum meyadari akan status penyu sebagai satwa lindung, sehingga masih terus ditangkap untuk dikonsumsi (Langinan, 2015, Balaira, 2016).

Selain itu, ancaman terhadap kelangsungan hidup penyu juga karena semakin terbatas lahan bertelur akibat konversi lahan pesisir pantai untuk pemukiman dan sarana umum. Sejauh ini lokasi bertelur penyu belum dipertimbangkan dalam pengelolaan wilayah pantai di kawasan ini. Hal ini terkait pulan dengan fakta bahwa lokasi bertelur penyu belum terdokumentasi dengan baik. Beberapa kegiatan inventasisasi lokasi bertelur penyu telah dilaporkan, antara lain oleh Kasenda (2014) untuk pantai timur Kabupaten Minahasa, dan Langinan (2015) untuk Pulau Karakelang.

\section{METODE PENELITIAN}

Survey dilakukan Pulau Salibabu, Kabupaten Kepulauan Talaud, Sulawesi Utara. Desa-desa di Pulau Salibabu merupakan desa pantai. Analisa data dan penulisan laporan dikerjakan di Lab Biologi Kelautan, Fakultas Perikanan dan IImu kelautan, Unsrat. Pengambilan data berlangsung selang Agustus-Desember 2016. Posisi geografis diperoleh dengan menggunakan GPS Magellan eXplorist 610. Data posisi geografis dipetakan dengan menggunakan Software ArcGIS. Data yang diperoleh melalui wawancara dengan warga lokal mencakup lokasi, nama pantai, waktu terakhir terlihat penyu bertelur dan jenis penyu yang bertelur. Vegetasi darat dominan dan bekas lubang tempat bertelur difoto. Sedimen pasir di sekitar lubang diambil untuk dianalisa di Laboratorium. Analisa pasir menggunakan ayakan glanolometri dengan klasifikasi sedimen menurut skala AFNOR (Association Francaise Pour La Normalisaton) (Pinot, 1992 dalam Kelah, 2004).

\section{HASIL DAN PEMBAHASAN}

Warga bermukin di pulau Salibabu pada umumnya mengetahui letak tempat bertelur penyu. Gambar 1 menujukkan bahwa $81 \%$ responden mengetahui tempat bertelur penyu di wilayah desanya. Informasi ditemukannya penyu bertelur dengan muda menyebar ke masyarakat karena hubungan social yang erat dan letak rumah warga yang terkonsentrasi pada suatu area pemukiman dalam desa. Selain itu, terkait pula dengan perilaku penyu yang selalu kembali ke tempat yang sama pada setiap musim reproduksi. Sekalipun sebagian besar responden mengetahui lokasi bertelur penyu namun yang melihat langsung penyu sedang bertelur hanya $32 \%$ (Gambar 2). Responden mengetahui lokasi bertelur penyu pada umumnya, $68 \%$ melalui informasi dari tetangga, kerabat dan nelayan. Hal ini tentu terkait dengan kebiasaan penyu melakukan aktivitas bertelur pada malam hari dan letak lokasi bertelur pada umumnya di luar kawasan pemukiman. Dengan demikian, yang berpeluang melihat langsung adalah mereka yang memiliki tujuan khusus untuk menangkap penyu atau para 


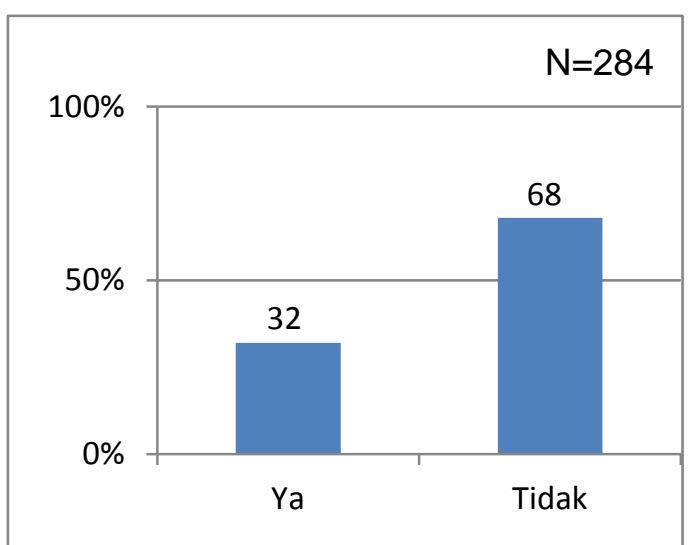

Gambar 1. Respon atas pertanyaan, apakah anda mengetahui tempat peneluran penyu di wilayah desa.

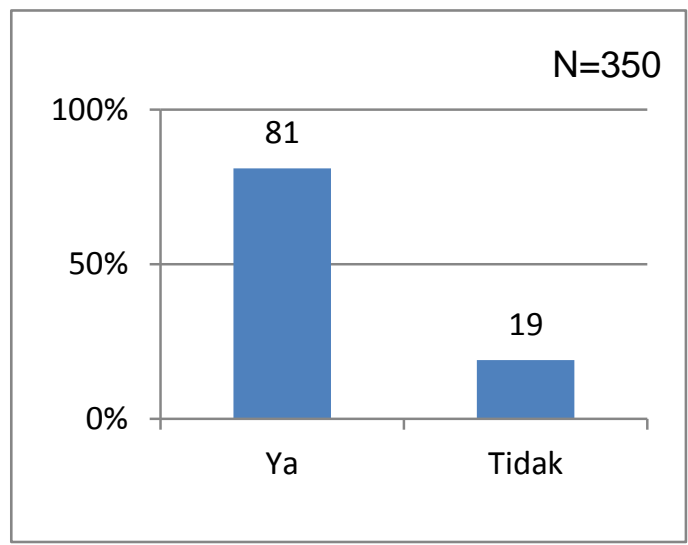

Gambar 2. Respon atas pertanyaan, pernahkah anda melihat secara langsung penyu bertelur di wilayah desa ini?

nelayan yang sering melintas kawasan pantai tersebut. Hal berbeda diperoleh dari studi di pantai utara Minahasa, dimana sebagian besar lokasi bertelur penyu berdekatan atau telah menjadi wilayah pemukiman serta objek wisata sehingga aktvitas bertelur lebih sering ditemukan oleh warga setempat (Boneka dan Wagey, 2016).

Berikut ini keterangan singkat tentang lokasi bertelur penyu.

Pantai Kalongan terletak 2-3 km dari wilayah pemukiman, jenis penyu hijau yang bertelur di lokasi ini, terlihat terakhir pada Pebruari 2014. Vegetasi darat yang umum adalah kelapa ( $C$. nucifera), pandan pantai ( $P$. tectorius).

Pantai Pasir Panjang terletak sekitar $1 \mathrm{~km}$ dari perkampungan desa Alude, jenis penyu hijau terlihat terakhir pada Mei 2015 dan penyu belimbing erlihat terakhir tahun 1980. Tumbuhan darat yang dominan di sekitar lokasi adalah pohon kelapa, ketapang, pohon bitung (Barringtonia asiatica), tumbuhan menjalar tapak kuda (Ipomoea pes caprae).

Pantai Rammenna: terletak sekitar $2 \mathrm{~km}$ dari pemukiman desa Dalum, penyu hijau terlihat terakhir pada Maret 2016; tanaman pantai dominan terdiri dari kepala, bitung dan tumbuhan menjalar. Pantai Matandikka terletak sekitar $2 \mathrm{~km}$ dari pemukiman desa Dalum, terlihat terakhir oleh warga penyu hijau bertelur pada Agustus 2015. Tumbuhan darat yang dominan adalah kelapa, bitung ( $B$. asiatica)

Pantai Apai: terletak sekitar 1 $\mathrm{km}$ dari pemukiman desa Bitunuris, penyu hijau bertelur terlihat terakhir oleh warga pada September 2015, tumbuhan di sekitar lokasi terdiri dari kelapa, pandan dan tapak kuda.

Pantai Tarawatta terletak $1,5 \mathrm{~km}$ dari wilayah pemukiman desa Bitunuris, penyu hijau terlihat pada Januari 2014. Tumbuhan yang umum di sekitar lokasi adalah kelapa, pandan pantai dan tapak kuda.

Pantai Dingkaren terletak $3 \mathrm{~km}$ dari pemukiman desa Bitunuris Selatan, penyu hijau terlihat bertelur pada Mei 2012. Tumbuhan yang mendominasi terdiri dari kelapa dan pandan pantai.

Pantai Pasir Putih: terletak sekitar 3,5 km dari pemukiman desa Bitunuris Selatan, penyu hijau terlihat terakhir pada Maret 2011 dan penyu sisik terlihat pada Oktober 2013. Tumbuhan darat dominan adalah kelapa dan pandan pantai.

Pantai Lairre: terletak sekitar 4 $\mathrm{km}$ dari pemukiman desa Bitunuris Selatan, penyu hijau terakhir terlihat bertelur pada Mei 2011. Tumbuhan yang mendominasi di sekitar tempat 


\begin{tabular}{|c|c|c|c|}
\hline No & Nama Pantai & Posisi Geografis & Wilayah Desa \\
\hline 1 & Kalongan & $4^{\circ} 0^{\prime} 24,12 "$ LU \& $126^{\circ} 36^{\prime} 51,02^{\prime \prime}$ BT & Kalongan \\
\hline 2 & Pasir Panjang & $3^{\circ} 59^{\prime} 5,12^{\prime \prime}$ LU \& $126^{\circ} 38^{\prime} 36,11^{\prime \prime}$ BT & Alude \\
\hline 3 & Rammenna & $3^{\circ} 51^{\prime} 4,55^{\prime \prime}$ LU \& $126^{\circ} 40^{\prime} 32,53^{\prime \prime}$ BT & Dalum \\
\hline 4 & Matandikka & $3^{\circ} 51^{\prime} 22,17^{\prime \prime}$ LU \& $126^{\circ} 40^{\prime} 33,47^{\prime \prime}$ BT & Dalum \\
\hline 5 & Apai & $3^{\circ} 49^{\prime} 58,03^{\prime \prime}$ LU \& $126^{\circ} 40^{\prime} 37,21^{\prime \prime}$ BT & Bitunuris \\
\hline 6 & Tarawatta & $3^{\circ} 50^{\prime} 46,24 "$ LU \& $126^{\circ} 40^{\prime} 32,76^{\prime \prime}$ BT & Bitunuris \\
\hline 7 & Dingkaren & $3^{\circ} 49^{\prime} 11,03^{\prime \prime}$ LU \& $126^{\circ} 42^{\prime} 19,31 "$ BT & Bitunuris Selatan \\
\hline 8 & Pasir Putih & $3^{\circ} 49^{\prime} 0,05^{\prime \prime}$ LU \& $126^{\circ} 42^{\prime} 17,88^{\prime \prime}$ BT & Bitunuris Selatan \\
\hline 9 & Lairre & $3^{\circ} 48^{\prime} 43,04^{\prime \prime}$ LU \& $126^{\circ} 41^{\prime} 18,57^{\prime \prime}$ BT & Bitunuris Selatan \\
\hline 10 & Batupenga & $3^{\circ} 49^{\prime} 11,97^{\prime \prime}$ LU \& $126^{\circ} 41^{\prime} 4,95^{\prime \prime}$ BT & Bitunuris Selatan \\
\hline
\end{tabular}

Tabel 1. Tempat bertelur penyu.

bertelur adalah pandan pantai dan kelapa.

Pantai Batupenga: terletak sekitar 2,5 km dari pemukiman desa Bitunuris Selatan, penyu hijau terlihat terakhir pada Mei 2015 dan penyu sisik pada April 2007. Tumbuhan yang mendominasi adalah kelapa, bitung, ketapang.

Gambar 3 menunjukkan distribusi tempat bertelur penyu di pulau Salibabu; dari kesepuluh lokasi, delapan terletak di bagian selatan atau wilayah desa Bitunuris, Bitunuris Selatan dan dalum dan hanya dua lokasi di pantai bagian yakni di wilayah desa Kalongan dan Alude. Penyebaran tempat bertelur yang hanya terdapat di bagian selatan dan utara, belum sepenuhnya dimengerti. Di bagian tengah pulau Salibabu terdapat sejumlah desa mencakup kecamatan lirung dan Moronge.

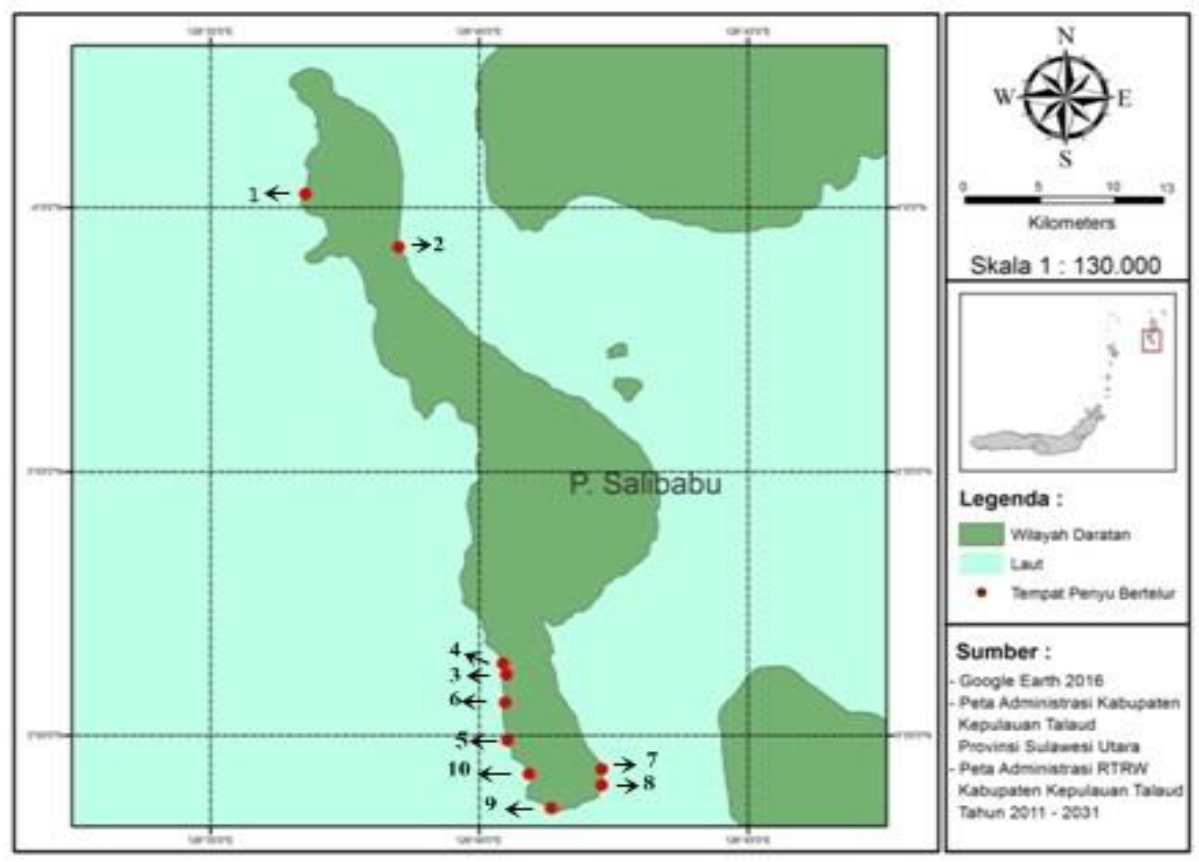

Gambar 3. Lokasi bertelur penyu di Pulau Salibabu 


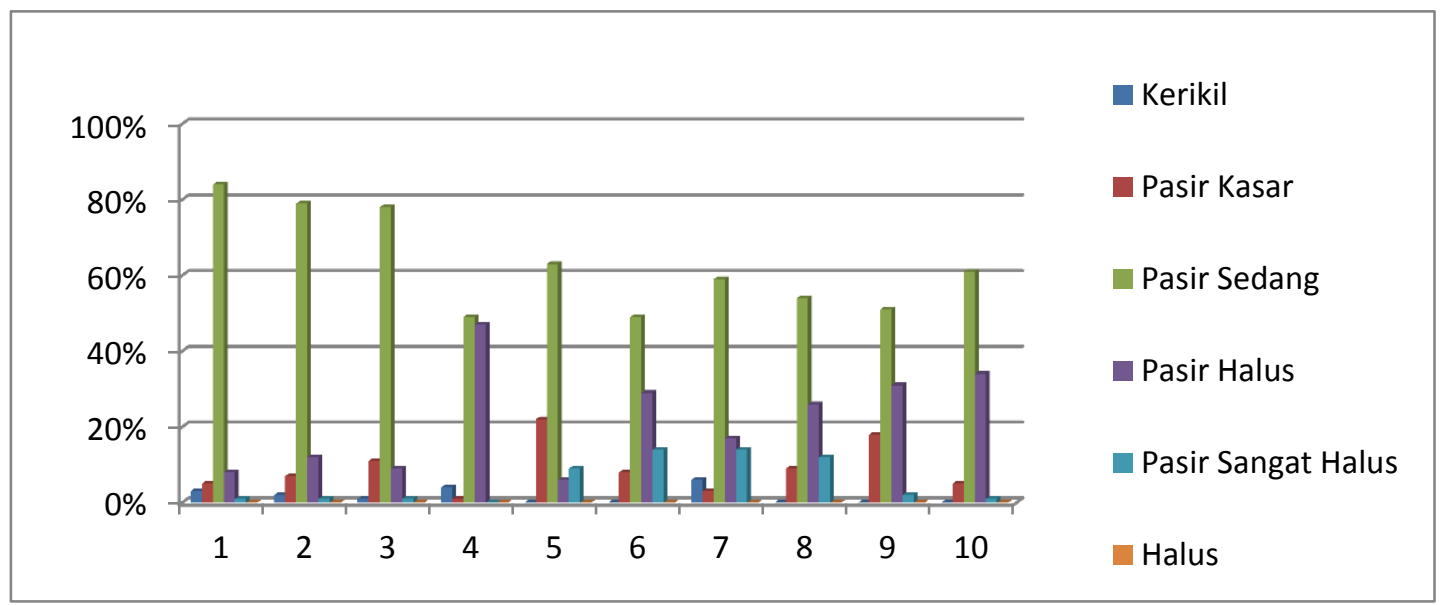

Gambar 4. Komposisi jenis sedimen di 10 lokasi

Pada Gambar 4 ditunjukkan komposisi jenis sedimen menurut ukuran butir skala AFNOR. Nomor 1-10 adalah lokasi dengan nama sesuai penomoran pada Tabel 1. Semua lokasi bertelur penyu didominasi oleh sedimen kategori pasir sedang $(0,800-$ $0,314 \mathrm{~mm})$, disusul pasir halus $(0,315-$ $0,125 \mathrm{~mm}$ ). Komponan sedimen pasir sedang di lubang penempatan telur oleh penyu diduga berkorelasi dengan (1) mengurangi resiko runtuh pada saat menggali lubang dan melepaskan telur oleh induk, (2) penetrasi oksigen dan resapan air, (3) kemudahan bagi tukik untuk keluar dari dalam lubang penetasan. Bila pasir halus dominan kemungkinan dapat menyulitkan penyu untuk menggali lubang dan tukik untuk keluar karena kemampatannya; sebaliknya jika pasir kasar atau berkerikil terlalu dominan, maka lubang mudah runtuh. Kecenderungan komposisi sedimen kategori pasir sedang dominan di sekitar lubang tempat bertelur penyu dinyatakan pula oleh Pradana et al (2013).

\section{KESIMPULAN}

Warga desa di pulau Salibabu Talaud pada umumnya dan mengetahui setiap lokasi bertelur penyu di wilayah desanya dan mengenal 3 jenis penyu yakni penyu Hijau, Sisik dan penyu Belimbing.Di pulau Salibabu terdapat 10 lokasi bertelur penyu, menyebar di lima wilayah desa yakni desa Kalongan (1), Alude (1), Dalum (2), Bitunuris (2) dan Bitunuris Selatan (4). Kesepuluh lokasi bertelur penyu terletak di luar wilayah pemukiman, dan pada umumnya berbatasan dengan perkebunan kelapa milik warga. Komposisi sedimen pada sekitar lubang bertelur penyu, didominasi oleh pasir sedang (ukuran partikek 0,800 $0,314 \mathrm{~mm}$ ).Sepatutnya lokasi bertelur penyu dilindungi dan dijadikan kawasan konservasi penyu.

\section{DAFTAR PUSTAKA}

Balaira, E. 2016. Kendala Konservasi Penyu Di Pulau Salibabu KabupatenTalaud. Laporan PKL, Fakultas Perikanan dan IImu Kelautan, Universitas Sam Ratulangi. Manado.

Boneka, F.B., Wagey, B.Th. 2016. Inventarisasi tempat bertelur penyu di pantai Utara Semenanjung Minahasa. Laporan Akhir RUPT Unsrat 2016.

DKP (Departemen Kelautan dan Perikanan). 2009. Pedoman Teknis Pengelolaan Konservasi Penyu. Diterbitkan oleh Direktorat Konservasi dan Taman Nasional Laut, Direktorat Jenderal Kelautan, Pesisir dan 
Pulau-Pulau Kecil, Departemen Kelautan dan Perikanan RI.

Kasenda, P.S. 2014. Lokasi Bertelur Penyu di Pantai Timur Kabupaten Minahasa Provinsi Sulawesi Utara. SKRIPSI.

Fakultas Perikanan dan IImu Kelautan UNSRAT. Manado.

Kelah, R. H. 2004. Morfometri Lahandan Distribusi Granolometri Sedimen terumbu Pinggiran Pantai Alar Pondang Minahasa Selatan SKRIPSI. Fakultas Perikanan dan IImu Kelautan UNSRAT.Manado.

Langinan, F. 2015. Persepsi Masyarakat Tentang Konservasi Penyu di Pulau Karakelang Kepulauan Talaud. Laporan PKL, Fakultas Perikanan dan Ilmu Kelautan, Universitas Sam Ratulangi. Manado.

Pradana, A.F., Said, S., Siahaan, S.2013. Habitat Tempat Bertelur Penyu Hijau (Chelonian Mydas) di Kawasan Taman Wisata Alam Sungai Liku KabupatenSambas Kalimantan Barat. Fakultas Kehutanan Universitas Tanjung Pura.Jurnal hutan lestari. Vol 1. 